\title{
Determination of Activity Coefficient of Lanthanum Chloride in Molten LiCl-KCl Eutectic Salt as a Function of Cesium Chloride and Lanthanum Chloride Concentrations Using Electromotive Force Measurements
}

\author{
Prashant Bagri ${ }^{\mathrm{a}, *}$, Michael F. Simpson ${ }^{\mathrm{a}}$ \\ ${ }^{a}$ Department of Metallurgical Engineering, University of Utah, 135 S 1460 E Rm 412, \\ Salt Lake City, Utah
}

\begin{abstract}
The thermodynamic behavior of lanthanides in molten salt systems is of significant scientific interest for the spent fuel reprocessing of Generation IV reactors. In this study, the apparent standard reduction potential (apparent potential) and activity coefficient of $\mathrm{LaCl}_{3}$ were determined in a molten salt solution of eutectic $\mathrm{LiCl}-\mathrm{KCl}$ as a function of concentration of $\mathrm{LaCl}_{3}$. The effect of adding up to 1.40 mole $\% \mathrm{CsCl}$ was also investigated. These properties were determined by measuring the open circuit potential of the La- $\mathrm{La}$ (III) redox couple in a high temperature molten salt electrochemical cell. Both the apparent potential and activity coefficient exhibited a strong dependence on concentration. A low concentration (0.69 mole \%) of $\mathrm{CsCl}$ had no significant effect on the measured properties, while a higher concentration (1.40 mole \%) of $\mathrm{CsCl}$ caused an increase (become more positive) in
\end{abstract}

\footnotetext{
${ }^{*}$ Corresponding author

Email address: prashant.bagri@utah.edu (Prashant Bagri)
}

Preprint submitted to Journal of Nuclear Materials

September 28, 2016

(C) 2016. This manuscript version is made available under the Elsevier user license http://www.elsevier.com/open-access/userlicense/1.0/ 
the apparent potential and activity coefficient at the higher range of $\mathrm{LaCl}_{3}$ concentrations.

Keywords: Activity Coefficient, Molten Salt Electrochemistry, Lanthanum Chloride, Cesium Chloride, Apparent Potentials

\section{Introduction}

2

The behavior of lanthanides in molten salt systems is of great scientific curiosity for the research, development and commercialization of Generation IV reactor candidates. The pyrochemical treatment of spent nuclear fuel (pyroprocessing) also represents a promising alternative to the aqueous processing of oxide fuel[1-3]. In the pyroprocessing scheme, the uranium and transuranics are separated from the bulk of the spent nuclear fuel using an electrolytic cell called an electrorefiner. During electrorefining, the spent nuclear fuel is placed in anode baskets. The cathode is either a steel cylinder or a crucible containing a liquid metal like cadmium. The electrolyte used for pyrochemical reprocessing is eutectic $\mathrm{LiCl}-\mathrm{KCl}$ molten salt which contains nominally 5 to $10 \mathrm{wt}$. $\% \mathrm{UCl}_{3}$. One of the major objectives of recent research in pyroprocessing has been towards understanding how to efficiently recover actinides from the electrorefiner and prevent their loss to waste streams. During normal operations, transuranic actinides and other active metal fission products accumulate in the salt as chlorides. To achieve high levels of actinide recovery in the process, these actinides must be separated from the salt prior to disposal of the salt. This is commonly referred to as actinide drawdown. A promising option for actinide drawdown is electrolytic reduction onto either a solid or liquid cathode coupled with 
evolution of chlorine gas at an inert anode. In theory, the actinides can be reduced first, due to their higher electrochemical nobility, leaving the rare earths in the salt. However, in some cases, the standard reduction potentials for actinides and rare earths are quite close and may result in co-deposition of unwanted rare earth metals. Standard reduction potentials do not take into account the non-ideal behavior of solutions. Understanding the behavior of these species in molten salt systems will aid in the design and development of optimized electrolytic systems. It is imperative to be able to predict the reduction potentials of actinides and rare earths at conditions of interest including varying compositions of complex salt mixtures and temperatures.

The development of highly accurate, predictive thermodynamic models for the pyrochemical treatment of spent nuclear fuel is critical for many other aspects of commercialization; development of on-line sensors, assessment of corrosion processes, and advancement of salt treatment methods to enable waste minimization. For the development of such models, one of the most fundamental yet esoteric quantities of interest are species' activity coefficients. Unlike gases where the fugacity can be calculated from first principles by determining the partition functions, for liquids there presently exists no grand unifying theory to calculate the activities from first principles. Activities have to be determined empirically for a given mixture, and the results are unique to that mixture and its individual constituents. For pyrochemical reprocessing of spent nuclear fuels in molten salts, the empirical determination of activities is further complicated by the quagmire of esoteric thermodynamic formalisms.

For $\mathrm{LaCl}_{3}$ in molten eutectic $\mathrm{LiCl}-\mathrm{KCl}$ salt, the activity coefficient has 
been previously measured experimentally by a number of groups over the years [4-8]. Activity coefficient of lanthanides like $\mathrm{Gd}, \mathrm{Nd}$, Ce has been measured by a much larger group of authors. A good summary of the data was published by Zhang[9] recently. One of the common themes of the studies to date has been the inherent presumption that the activity coefficients are independent of concentration of analyte present in solution. The activity coefficient of lanthanum chloride has been studied only at single concentration in these studies. There is significant divergence in the data reported in literature. One of the contributing factors for such divergence may be the fact that every study was performed at a different concentration of $\mathrm{LaCl}_{3}$. Looking at analogous aqueous chemistry literature, it has been reported [10] that the activity coefficient of metal ions in aqueous solutions varies with concentration. No such study has been performed for La(III) ions in molten chloride salt.

Cesium is an important fission product that can accumulate in the electrolyte in the molten salt over time. Large amounts of accumulated cesium in the electrorefiner electrolyte can interfere with the separation process for the uranium and transuranics. This would require the either the eventual replacement of the electrolyte or the selective extraction of cesium from the salt. One of the proposed flow sheets for the further reduction in total waste is the Rare Earth Drawdown (REDD) process [11]. REDD can be a useful process for minimizing the amount of waste generated by selectively separating rare earth fission products from Group I and II metals in the salt thus enabling recycling of the eutectic $\mathrm{LiCl}-\mathrm{KCl}$ electrolyte back to the electrorefiner. One of the motivations of this paper is to study the concentrations at which the 
presence of $\mathrm{CsCl}$ will begin to affect the properties of the lanthanides in the molten salts, to enable us to predict and anticipate the levels of $\mathrm{CsCl}$ concentrations would be a cause of concern from a reprocessing standpoint.

In this study, we present a thermodynamic framework for determining the activities of species in dissolved molten salts and further present experimentally determined activity coefficient of $\mathrm{LaCl}_{3}$ in molten eutectic $\mathrm{LiCl}-\mathrm{KCl}$ salt. Further, we will look at the effects of concentration of $\mathrm{LaCl}_{3}$ and the effect of cesium chloride on the activity coefficient of $\mathrm{LaCl}_{3}$.

\section{Experimental}

\subsection{Equipment and Reagents}

All the experiments were performed inside an ultra-dry argon atmosphere $\left(\leq 0.1 \mathrm{ppm} \mathrm{O}_{2}\right.$ and $\left.\leq 0.1 \mathrm{ppm}_{2} \mathrm{O}\right)$ glovebox (Innovative Technologies). A Kerr furnace was used to heat the salts to the desired temperature. The salts were heated in SIGRADUR ${ }^{\circledR}$ glassy carbon crucibles (HTW Germany). A two-electrode electrochemical cell was set-up to perform open circuit potential (OCP) measurements. The working electrode was a perforated stainless steel basket into which a lanthanum metal rod was placed. The counter/reference electrode was a 5 mole $\% \mathrm{Ag} / \mathrm{AgCl}$ reference electrode. The reference electrode was encased in a Pyrex tube (Wilmad ${ }^{\circledR}$ Sigma Aldrich; $100 \mathrm{MHz} ; 10 \mathrm{~mm}$ diameter). The temperature of the molten salt was measured using RTD thermocouples (Omega). The OCP was measured using an Autolab potentiostat (MetrohmUSA). Though nominal concentrations were based on mass of salts added to the mixtures, actual concentrations of lanthanum in the salt mixture were determined using an inductively cou- 
pled plasma - optical emission spectroscopy (ICP-OES) instrument (Spectro Genesis). Actual cesium concentration was determined using an inductively coupled plasma - mass spectrometry (ICP-MS) instrument (Agilent Technologies). All samples were weighed on a precision balance (Mettler Toledo). Precision balances are susceptible to drift due to build-up of static charges which is aggravated with balances placed inside a dry atmosphere glovebox. A vial full of radioactive material (uranium oxide) was always kept inside the precision balance to neutralize the static charges.

Reagents used for this study were as follows: Ultra dry $99.99 \% \mathrm{LiCl}-\mathrm{KCl}$ (Sigma-Aldrich), 99.998 \% ultra-dry cesium chloride salt (Alfa Aesar), 99.99 $\%$ ultra-dry lanthanum chloride salt (Alfa Aesar) and lanthanum metal rod (6.35 mm x $25 \mathrm{~mm}$; $99.9 \%$ Alfa Aesar), silver chloride (99.997 \% metals basis; Alfa Aesar), silver wire (1 mm diameter, $99.9 \%$ metal basis; Alfa Aesar). Standards for ICP calibration were procured from Inorganic Ventures.

\subsection{Experimental Procedure}

A schematic of the experimental set-up is shown in Figure 1. This set-up was used for all of the experiments unless otherwise stated. For studying the activity coefficient as a function of $\mathrm{LaCl}_{3}$ concentration, pre-weighed quantity of pure $\mathrm{LiCl}-\mathrm{KCl}$ salt was heated to the desired temperature (773 K). Subsequently, pre-weighed quantities of $\mathrm{LaCl}_{3}$ were added to this molten salt progressively. After every addition of $\mathrm{LaCl}_{3}$, the solution was allowed to stand and equilibrate. The stainless steel basket with the lanthanum metal rod was then inserted into the molten salt mixture and open circuit potential (OCP) measurements were made. After such a measurement, $\mathrm{LaCl}_{3}$ was again added and the process was repeated. After every OCP measurement, 
a sample was taken using a stainless steel all-thread rod. For tests with $\mathrm{CsCl}$ present, the initial melt consisted of LiCl-KCl-CsCl. During the life of the tests, small quantities of $\mathrm{CsCl}$ were added to prevent dilution of $\mathrm{CsCl}$ concentration. The remaining experimental methodology was similar to the one described above.

The glassy carbon crucible is a conductor of electricity. To ensure that there were no mixed potential artifacts between the crucible and working electrode, we ensured that the working electrode was never in physical contact with the glassy carbon crucible. The working electrode basket was held suspended in the molten salt with the help of alligator clips, which were resting against the alumina lid used for the experiments. Additionally any mixed potential effects associated with the stainless steel basket and La metal rod, we believe should be negligent. Iron (the predominant constituent in stainless steel) is electrochemically nobler than lanthanum in molten LiCl-KCl eutectic salt [12]. For any significant mixed potential effects to be present, the $\mathrm{Fe}(\mathrm{II}) / \mathrm{Fe}(0)$ half-cell reaction must proceed forward, driving the $\mathrm{La}(\mathrm{III}) / \mathrm{La}(0)$ half-cell reaction backwards. In our working electrolyte, no significant quantities of Fe(II) are present (apart from impurities), for this to be a cause of concern.

\section{Theory}

\subsection{Experimental Determination of Activity Coefficients}

In this section, the theoretical basis for determining the activity coefficient from an electrochemical cell will be presented. Consider a metal $M$ and its dissolved species $M^{n+}$. An elementary reversible reaction can be written as 
shown in Equation 1

$$
M^{n+}+n e^{-}=M^{0}
$$

For Equation 1, the Nernst equation can be written as shown in Equation 2

$$
E^{e q}=E^{0}-\frac{R T}{n F} \ln \left(\frac{a_{M^{0}}}{a_{M^{n+}}}\right)
$$

In Equation 2, $R$ is the universal gas constant, $T$ is the temperature in Kelvin, $n$ is the number of electrons transferred in Equation 1 and $F$ is Faraday's constant. $a_{M^{0}}$ and $a_{M^{n+}}$ are the activities of $M^{0}$ and $M^{n+}$. $E^{e q}$ is the equilibrium potential and $E^{0}$ is the standard reduction potential. In general, $E^{0}$ is defined as the potential when a pure metal $M$ is in equilibrium with its pure dissolved ion $M^{n+}$ at the temperature of interest. We know from thermodynamics that $a_{M^{0}}=1$, since it is a pure solid. Hence Equation 2 can be re-written as follows:

$$
E^{e q}=E^{0}+\frac{R T}{n F} \ln \left(a_{M^{n+}}\right)
$$

but,

$$
a_{M^{n+}}=\gamma_{M^{n+}} X_{M^{n+}}
$$

where $\gamma_{M^{n+}}$ and $X_{M^{n+}}$ represent the activity coefficient and mole fraction of species $M^{n+}$ respectively. Substitute Equation 4 in Equation 3,

$$
E^{e q}=E^{0}+\frac{R T}{n F} \ln \left(\gamma_{M^{n+}} X_{M^{n+}}\right)
$$

Re-arranging the terms, 


$$
E^{e q}=E^{0}+\frac{R T}{n F} \ln \left(X_{M^{n+}}\right)+\frac{R T}{n F} \ln \left(\gamma_{M^{n+}}\right)
$$

Equation 6 can be re-written as follows:

$$
E^{e q}-\frac{R T}{n F} \ln \left(X_{M^{n+}}\right)=E^{0}+\frac{R T}{n F} \ln \left(\gamma_{M^{n+}}\right)
$$

In deriving Equation 7, Equation 4 is used which defines the activity of the solute as a product of activity coefficient and mole fraction. The Nernst equation can be written correctly for any of the three concentration scales of molarity, molality and mole fraction[13, 14]. Depending on the concentration scale used, the standard states for each of these concentration scales must be defined adequately. Hence each of the concentration scales there will be unique values of standard reduction potential $\left(E^{0}\right)$ designated as $E_{M}^{0}, E_{m}^{0}$ and $E_{X}^{0}$ for molarity, molality and mole fraction respectively $[13,14]$. For this study, the standard state used is the Pure Supercooled Liquid $\mathrm{LaCl}_{3}$ i.e. $X_{\mathrm{LaCl}_{3}}=1$. The mole fraction scale is more convenient to use for molten salt systems than the molarity scale as it is independent of density and temperature. This is also the scale most widely used in the molten salt literature hence comparable thermodynamic data is more easily available. Density of salts is extremely hard to measure accurately due to solute effects. Hence we derive the Nernst equation on the mole fraction scale.

All of the terms on the left hand side (LHS) of Equation 7 are known. We would measure $E^{e q}$ in an electrochemical cell (as the OCP). Knowing the concentration of the species present, $X_{M^{n+}}$ can be calculated. Thus, using Equation 7 we can calculate the Apparent Potential $\left(E^{0^{\prime}}\right) . E^{0^{\prime}}$ is defined as shown in Equation 8. Bard and Faulkner[15] call the term $E^{0^{\prime}}$ as the Formal 
Potential.

$$
E^{0^{\prime}}=E^{0}+\frac{R T}{n F} \ln \left(\gamma_{M^{n+}}\right)
$$

The right hand sides (RHS) of both Equations 7 and 8 are the same. Hence we can equate the left hand sides of the aforementioned equations and obtain the value of $E^{0^{\prime}}$. Knowing $E^{0^{\prime}}$, we can determine the value of $\gamma_{M^{n+}}$ from Equation 8 if we know the value of the only other unknown quantity; $E^{0}$. As mentioned earlier, in the purist sense, $E^{0}$ for the La(0)-La(III) system, will be the equilibrium potential when pure La metal is in equilibrium with pure La(III) (lanthanum chloride) at the temperature of interest $(773 \mathrm{~K}$ ). The electrorefining of the spent fuel in eutectic salt is carried out at 773 K. Pure lanthanum chloride melts at $1131 \mathrm{~K}$, hence it is not possible to obtain a true value of $E^{0}$ for lanthanum chloride for molten eutectic salt mixtures. This is also true for other lanthanides and actinides that have the melting temperature of the pure salt above the working temperature of an electrorefiner. Due to this conundrum, there is clearly a need to define the activity of La(III) versus a different standard state. For that we delve into the most basic definition of activities for real solutions. In general, activity of any species ' $i$ ' can be defined as shown in Equation 9.

$$
\bar{G}_{i}=\bar{G}_{i}^{0}+R T \ln a_{i}
$$

In Equation 9, $\bar{G}_{i}$ is the partial molar Gibbs free energy (chemical potential) of the species ' $i$ ' and $\bar{G}_{i}^{0}$ is the partial molar Gibbs free energy of the species ' $i$ ' at the standard state (equivalent to the molar Gibbs free energy of the pure species). We can choose to define the standard state with 
the most appropriate conditions of extensive thermodynamic properties. For molten salt systems, if we want to measure the deviation from ideal behavior, $\bar{G}_{i}^{0}$ must be defined as the chemical potential of the 'Pure Supercooled Liquid Salt'[16]. This is the reference that has been used by various authors that have experimentally determined the activity coefficient of lanthanum chloride. Some authors have mistakenly used the value of Gibbs free energy of formation of pure crystal as the reference/standard state. Such a standard state has no physical meaning and is inherently inaccurate. The 'Pure Supercooled Liquid $\mathrm{LaCl}_{3}$ ' standard state will be used in this work.

Converting potential to Gibbs free energies using the relationship $\Delta G=$ $-n F E$ and replacing the value of $\Delta G^{0}$ with $\Delta G^{S C}$, the Gibbs free energy of Pure Supercooled Liquid. Now, Equation 8 can be re-written as follows:

$$
\Delta G^{S C}-\Delta G^{0^{\prime}}=R T \ln \left(\gamma_{M^{n+}}\right)
$$

The term $\Delta G^{S C}-\Delta G^{0^{\prime}}$ is also known as the Gibbs Excess Free Energy $\left(\Delta G^{\text {Excess }}\right.$ ). The term $\Delta G^{\text {Excess }}$ captures the deviation from ideal behavior of a liquid mixture[17]. For ideal solutions, $\Delta G^{\text {Excess }}$ is zero. Equation 10 can be re-written as follows:

$$
\Delta G^{\text {Excess }}=\Delta G^{S C}-\Delta G^{0^{\prime}}=R T \ln \left(\gamma_{M^{n+}}\right)
$$

Using Equation 11, the activity coefficient (and by extension the activity) of a species can be calculated. The only unknown in this equation is the value of $\Delta G^{S C}$. A detailed discussion on how to determine this value is provided in the next subsection. 


\subsection{Determination of $\Delta G^{S C}$}

In general, we can define a change in Gibbs free energy of fusion $\left(\Delta G_{\text {Fusion }}\right)$ in Equation 12, where $G_{\text {PureLiquid }}$ and $G_{\text {PureSolid }}$ are the chemical potentials of pure liquid and pure solid respectively.

$$
\Delta G_{\text {Fusion }}=G_{\text {PureLiquid }}-G_{\text {PureSolid }}
$$

If we are at temperatures below the melting point of the species, as is the case for $\mathrm{LaCl}_{3}$ at $773 \mathrm{~K}$ here, then $\Delta G_{\text {Fusion }}$ is the hypothetical free energy of fusion, $G_{\text {PureLiquid }}$ is equal to the chemical potential of the pure supercooled liquid $\left(G^{S C}\right)$, our desired standard state for determination of activity coefficients, and $G_{\text {PureSolid }}$ is equal the Gibbs free energy of formation of pure crystal $\left(G_{\text {Formation }}\right)$ at the temperature of interest $\left(\mathrm{T}_{\mathrm{i}}\right)$. Hence Equation 12 can be re-written as follows:

$$
\Delta G_{\text {Fusion }}^{\text {Hypothetical }}\left(T_{i}\right)=G^{S C}\left(T_{i}\right)-G_{\text {Formation }}\left(T_{i}\right)
$$

In Equation 13, ' $T_{i}$ ' represents the temperature (in Kelvin) for which the calculations are performed. For Equation 13 to be true as written, $T_{i}<T_{M}$, where $T_{M}$ is the melting point of the pure solid (For $\mathrm{LaCl}_{3}, T_{M}=1131$ $\mathrm{K})$. In Equation 13, the value of $G_{\text {Formation }}$ can be found in thermodynamic databases[18] or sources like the NIST-JANAF Thermochemical Tables. $G^{S C}$ is the unknown value of the "Pure Supercooled Standard State" we are trying to determine. In the next subsection, we will look at the method to determine the value of $\Delta G_{\text {Fusion }}^{\text {Hypothetical }}$. 


\subsubsection{Determination of $G_{\text {Fusion }}^{\text {Hypotical }}$}

In this section, we will look briefly at a general method to calculate the value of $G_{\text {Fusion }}^{\text {Hypotheal }}$. Figure 2 shows a schematic of the $\mathrm{H}$ vs. T diagram. $T_{i}$ and $T_{M}$ denote the temperature of interest for which the value of $G_{F u s i o n}^{\text {Hypotical }}$ (hereafter denoted as $G_{\text {Fusion }}$ ) needs to be calculated and the melting temperature of the substance respectively. On an $\mathrm{H}$ vs. T diagram, the slope of the lines is the $C_{p(S)}$ and $C_{p(L)}$, which denote the specific heat capacity of solid and liquid at temperatures lower and higher than $T_{M}$ respectively. The value of $\Delta G_{\text {Fusion }}$, can be determined as follows[19]:

At $T=T_{M}$,

$$
\Delta G_{\text {Fusion }}=\Delta H_{\text {Fusion }}-T_{M} \Delta S_{\text {Fusion }}=0
$$

The values of $\Delta H_{F u s i o n}$ and $\Delta S_{F u s i o n}$ at $T=T_{M}$ can be found in thermodynamic databases. At any other temperature of interest $\left(T_{i}\right)$, the values of $\Delta H_{\text {Fusion }}\left(T_{i}\right)$ and $\Delta S_{\text {Fusion }}\left(T_{i}\right)$ which are needed to calculate the value of $\Delta G_{\text {Fusion }}\left(T_{i}\right)$ can be calculated as shown in Equation 15 and 16, respectively.

$$
\begin{gathered}
\Delta H_{\text {Fusion }}\left(T_{i}\right)=\Delta H_{\text {Fusion }}\left(T_{M}\right)+\int_{T_{M}}^{T_{i}}\left(C_{p(\text { Liquid })}-C_{p(\text { Solid })}\right) d T \\
\Delta S_{\text {Fusion }}\left(T_{i}\right)=\Delta S_{\text {Fusion }}\left(T_{M}\right)+\int_{T_{M}}^{T_{i}} \frac{C_{p(\text { Liquid })}-C_{p(\text { Solid })}}{T} d T
\end{gathered}
$$

For the above calculations, the value of $C_{p(L)}$ is extrapolated below the melting point to the temperature of interest. Using Equations 15 and 16, the values of $\Delta H_{F u s i o n}\left(T_{i}\right)$ and $\Delta S_{\text {Fusion }}\left(T_{i}\right)$ can be calculated. The value of 
$\Delta G_{\text {Fusion }}\left(T_{i}\right)$ can then be calculated simply by using the standard thermodynamic relationship $\Delta G_{\text {Fusion }}\left(T_{i}\right)=\Delta H_{\text {Fusion }}\left(T_{i}\right)-T \Delta S_{\text {Fusion }}\left(T_{i}\right)$. After having calculated the values of $\Delta G_{F u s i o n}\left(T_{i}\right)$, the value of $\Delta G^{S C}\left(T_{i}\right)$ can be calculated using Equation 13. If $T_{i}<T_{M}$, then the value calculated using the above described method will be equal to $\Delta G^{S C}$. The value of $\Delta G^{S C}$ can now be used to calculate the activity coefficient from Equation 11.

In Equation 13, the value of $G_{\text {Formation }}$ at any desired temperature can be obtained readily from thermodynamic databases, software or from previously published literature. The accuracy with which the value of $G_{\text {Formation }}$ can be calculated in generally $\pm 10 \mathrm{~kJ} /$ mole. A survey of literature showed that at $773 \mathrm{~K}$, the reported values from Gibbs free energy of formation for a pure crystal $\mathrm{LaCl}_{3}$, were found to be $-880.9 \mathrm{~kJ} /$ mole (HSC Chemistry Software v. 7.11$),-896 \mathrm{~kJ} / \mathrm{mole}[7],-882.8 \mathrm{~kJ} / \mathrm{mole}[18]$ and $-900.8 \mathrm{~kJ} / \mathrm{mole}[20]$. Depending on the choice of reference for the Gibbs free energy of formation that was selected, the value of the activity coefficient would change by over three orders of magnitude. This is because as shown in Equation 11, the activity coefficient is an exponential function of the Gibbs free energy of formation. Rather than consider this as a source of error in the calculation of activity coefficients, it should be seen as the compelling reason why the data and methods used to calculate the standard state free energy of formation must be cited along with the values of the activity coefficients. Without such specific information, the activity coefficients are of no value as they are not uniquely defined. Using the theory presented above, we calculated the $\Delta G^{S C}$ values for $\mathrm{LaCl}_{3}$ as shown in Table 1. For these calculations, we used Thermochemical Data of Pure Substances [18] as the source. 


\section{Results}

In general, we observed that the OCP values recorded using the potentiostat were very stable to the third decimal place (which is the limit for the instrument) with fluctuations non-existent. Statistical analysis performed on a random sample of 17 independent OCP measurements yielded an average standard deviation of $0.120 \mathrm{mV}$ in the measurements. Using that data set, within a $95 \%$ confidence interval the average margin of error for the OCP measurement was calculated to be $0.04 \mathrm{mV}$. These statistical calculations help us perform error propagation analysis through the entire calculations. All the potentials reported in this paper are reported versus a $\mathrm{Cl}^{-} / \mathrm{Cl}_{2}$ reference electrode unless otherwise stated. Data reported by Yang and Hudson[21] was used to convert the potentials from the 5 mole $\%$ $\mathrm{Ag} / \mathrm{AgCl}$ reference electrode we used to the $\mathrm{Cl}^{-} / \mathrm{Cl}_{2}$ scale. In this section, we will now present results from the experiments for activity coefficient of $\mathrm{LaCl}_{3}$ first as a function of $\mathrm{LaCl}_{3}$ concentration. Next data will be presented on the effect of $\mathrm{CsCl}$ on the activity coefficient of $\mathrm{LaCl}_{3}$.

Figure 3 shows a cyclic voltammogram (CV) of lanthanum chloride present in molten eutectic salt. The CV was performed at four scan rates of 200, 300400 and $500 \mathrm{mV} / \mathrm{s}$. The La(III)/La(0) peak can be observed clearly in

Table 1: Calculated values of Gibbs Free Energy of Pure Supercooled $\mathrm{LaCl}_{3}$.

\begin{tabular}{cccccc}
\hline Temperature & $\Delta H_{\text {Fusion }}$ & $\Delta S_{\text {Fusion }}$ & $\Delta G_{\text {Fusion }}$ & $\Delta G_{\text {Formation }}$ & $\Delta G^{S C}$ \\
$($ Kelvin $)$ & $(\mathrm{kJ} / \mathrm{mole})$ & $(\mathrm{J} / \mathrm{K}$-mole $)$ & $(\mathrm{kJ} / \mathrm{mole})$ & $(\mathrm{kJ} / \mathrm{mole})$ & $(\mathrm{kJ} / \mathrm{mole})$ \\
\hline 773 & 41.813 & 34.507 & 15.139 & -882.767 & -867.628 \\
\hline
\end{tabular}


the CV and has been labeled. As expected, it is observed that the current increases with the scan rate. The main take away from the CV is that there is no other analyte species present in the molten salt electrolyte. Any $\mathrm{Cs}(\mathrm{I})$ present introduced in the form of $\mathrm{CsCl}$, will reduces at a potential more negative that the reduction potential of $\mathrm{Li}^{+} / \mathrm{Li}$ peak[12]. Hence $\mathrm{Cs}^{+} / \mathrm{Cs}$ reduction cannot readily be observed in the cyclic voltammetry scans.

\subsection{Effect of $\mathrm{LaCl}_{3}$ Concentration}

The calculation of activity coefficients from OCP measurements is an exponential mathematical relationship as described earlier. Even small errors in the measurements of the open circuit potentials will not only propagate through the calculations but indeed gets magnified as we go through our calculations. Hence we decided to smooth the open circuit potential measurements at this initial stage using a suitable function to prevent the further propagation and magnification of these errors. Matlab was used to generate this function, of the form $y=a e^{b x}+c e^{d x}$, from the experimental data.

The average difference between the measured and modeled values is observed to be about $2 \mathrm{mV}$ with a standard deviation of $1.4 \mathrm{mV}$. Such small errors are well within the realm of experimental error associated with physical measurements. Figure 4 shows the experimental values of OCP plotted along with the model fit. The coefficient of determination for the fit to function was greater than 0.99. For all further calculations, the values obtained from the best-fit functions were used rather than discrete measured data points.

Using the values obtained, we can calculate the apparent potential and activity coefficients of $\mathrm{LaCl}_{3}$ in the molten salt. Figure 5 shows a plot of the apparent potential $\left(E^{0^{\prime}}\right)$ plotted as a function of concentration. It can 
be observed that the value of the apparent potential is not a constant value as previously assumed and is indeed a function of concentration. The value of $E^{0^{\prime}}$ initially increases (becomes more positive) reaching its most positive value at about 0.55 mole \% La. It then proceeds to decrease (becomes more negative) and beginning to taper off at higher concentrations of $\mathrm{LaCl}_{3}$ towards a constant value. Within the concentration range tested, the electrochemical potential for the reduction of $\mathrm{La}(\mathrm{III})$ to $\mathrm{La}(0)$ varies by about $25 \mathrm{mV}$. Previously, Shirai et al.[22], Kuznetsov et al.[23] \& Tang and Pesic[6] independently reported the apparent potential of the La(III) - La(0) couple at $773 \mathrm{~K}$ to be $-3.137 \mathrm{~V},-3.079 \mathrm{~V}$, and -3.072 respectively. These values are of course outside of the potential window that reported in this paper. However, a closer look at the experimental methods employed by each of these authors likely explains why that is the case. Shirai et al.[22] used cyclic voltammetry $(\mathrm{CV})$ to determine the reduction potentials of the La(III) - La(0) couple. The use of CV's is not necessarily an optimal technique to determine equilibrium reduction potentials since the potentials measured during $\mathrm{CV}$ include overpotentials associated with nucleation and growth of the metal crystals on the cathode[24, 25]. Kuznetsov et al.[23] performed their experiments in a mixture of $\mathrm{LiCl}-\mathrm{KCl}-\mathrm{UCl}_{3}-\mathrm{LaCl}_{3}$ mixture. In such a scenario, there is likely to be other effects at play between the two analytes present. Tang and Pesic[6] meanwhile used equilibrium measurements. The only difference was that they used a molybdenum working electrode. They deposited some La metal on to the working Mo electrode and measured the OCP. This allowed for a very short time to study the open circuit potentials.

The activity coefficient of $\mathrm{LaCl}_{3}\left(\gamma_{\mathrm{LaCl}_{3}}\right)$, can now be calculated for each 
concentration of lanthanum chloride for which the open circuit potential measurements were performed using Equation 11. The standard state used for such calculations was the "Pure Supercooled Liquid Standard State," the calculations for which have been shown in the Table 1. Figure 6 shows a plot of activity coefficient as a function of $\mathrm{LaCl}_{3}$ concentration. We see that the activity coefficient of $\mathrm{LaCl}_{3}$ varies with concentration, initially increasing and subsequently decreasing, a function that is similar to the variation of apparent potential.

Previously from reports in the literature, the value of $\gamma_{\mathrm{LaCl}_{3}}$ has been assumed to be independent of concentration, presumably based on an assumptions regarding pseudo-ideal behavior of dilute solutions. Results reported here clearly show that the activity coefficient is a function of concentration of $\mathrm{LaCl}_{3}$ even at low concentrations of $\mathrm{LaCl}_{3}$. Previously various authors [4-7] have calculated the activity coefficients of $\mathrm{LaCl}_{3}$ from experimental measurements. From the above studies, Tang and Pesic[6] used values of $\Delta G^{S C}$ that are different from the ones used in this paper. They used HSC Chemistry software to perform these calculations. They report values which are three orders of magnitude greater than the ones we report here. Masset et al.[4] reported the value of $\gamma_{\mathrm{LaCl}_{3}}$ as 0.0057 at a concentration of $20 \times 10^{-5} \mathrm{~mole} / \mathrm{cm}^{3}$. That value is within the range of data reported here. Without knowledge of the density of the salt, it would be hard to convert that concentration to mole fraction accurately, for comparison. Castrillejo et al.[7] reported values at $723 \mathrm{~K}$ and $823 \mathrm{~K}$, not at $773 \mathrm{~K}$ as reported here. At $723 \mathrm{~K}$, they reported a value of 0.0053 for the activity coefficient of $\mathrm{LaCl}_{3}$. 


\subsection{Effect of Cesium Chloride}

The behavior of lanthanum chloride in the presence of Group I element Cs was also studied since it is a major fission products that accumulate in electrorefiner salt. For this study, $\mathrm{CsCl}$ was added to the salt at two concentrations- 0.69 mole \% (Standard Deviation: 0.04 mole \%) and 1.40 mole \% (Standard Deviation: 0.04 mole \%). We followed the same methodology for analysis as reported in the previous section including the fitting of OCP data to an interpolating function. The average difference between the experimentally measured values and modeled values was again found to be less than $2 \mathrm{mV}$. Figure 7 shows a plot of open circuit potentials for tests with three concentrations of $\mathrm{CsCl} ; 0,0.69$ and 1.40 mole \% $\mathrm{CsCl}$ as a function of $\mathrm{LaCl}_{3}$ concentration. It can be observed that there is not much difference between the open circuit potentials for La/La(III) for the tests with the two lowest concentrations of $\mathrm{CsCl}$ i.e. 0 and 0.69 mole \%. However, the equilibrium potentials for the La/La(III) couple show a notable positive shift in the presence of 1.40 mole $\% \mathrm{CsCl}$. This is only true at higher concentrations of $\mathrm{LaCl}_{3}$. At low concentrations of $\mathrm{LaCl}_{3}$, the equilibrium potentials for all of the three tests are fairly similar.

Figure 8 shows the plot of apparent potential $\left(E^{0^{\prime}}\right)$ as a function of $\mathrm{LaCl}_{3}$ concentrations, for three distinct concentrations of $0,0.69$ and 1.40 mole \% $\mathrm{CsCl}$. From the figure, we can observe that the nature of the graphs for all of the three tests is similar. All the three tests demonstrate that the apparent potential does indeed follow a pseudo Gaussian function, with a maximum at some concentration followed by a decline. Lower concentration (0.69 mole \%) of Cs does not seem to have a substantial impact on the apparent potential. 
However the presence of 1.40 mole \% Cs does seem to move the curve to the right and make the apparent potential of $\mathrm{LaCl}_{3}$ more positive. An additional observation is that, both without any $\mathrm{CsCl}$ and with the presence of 0.69 mole $\% \mathrm{CsCl}$, the apparent potential for $\mathrm{LaCl}_{3}$ reaches its most positive value at about 0.55 mole $\% \mathrm{LaCl}_{3}$.

Figure 9 shows the graph of activity coefficient of lanthanum chloride for the three concentrations of $\mathrm{CsCl}$. It is observed that the activity coefficient of $\mathrm{LaCl}_{3}$ increases in the presence of 1.40 mole $\% \mathrm{CsCl}$. The interaction of the lanthanum and cesium ions in the molten slat changes the activity coefficients of the ions. We presume that this is caused by the influence Cs ions have on the complexation and coordination chemistry of lanthanum ions dissolved in the molten salt.

It is important to consider if the effects of $\mathrm{CsCl}$ observed and reported here are statistically significant. For this purpose, the Student's t-test was employed. Analyzing the apparent potential data using the t-test indicates that we can say with at least $95 \%$ confidence that the difference in the apparent potentials of the tests with $0 \& 0.69$ mole $\% \mathrm{CsCl}$ are statistically insignificant. Further, the difference in the apparent potentials of the tests with $0.69 \& 1.40$ mole $\% \mathrm{CsCl}$ is statistically significant (within a $95 \%$ confidence interval) A similar conclusion can be made about the activity coefficients of the three data sets where there is observed to be a statistical difference between the activity coefficients of the tests with $1.40 \% \mathrm{CsCl}$ and the other two tests. 


\section{Discussion}

From the data presented above, it is evident that the activity coefficient of $\mathrm{LaCl}_{3}$ dissolved in molten eutectic LiCl-KCl salt is dependent on the concentration of $\mathrm{LaCl}_{3}$ dissolved in solution and not just a single value as previously reported. Recently Wang et al.[26] published a very detailed study looking into the activity coefficient and apparent potentials of $\mathrm{LaCl}_{3}$ as a function of concentration of $\mathrm{LaCl}_{3}$ using Molecular Dynamic Simulations (MDS). The results presented here differ only meaningfully from the ones presented by Wang et al.[26] at the higher concentrations of $\mathrm{LaCl}_{3}$ where in we report a decline in both the apparent potential and activity coefficient wheres they report a linear dependence throughout the concentration range of up to 3 mole $\% \mathrm{LaCl}_{3}$. Additionally, there is extensive documentation of such concentration dependence of activity coefficient within the more vigorously researched field of aqueous chemistry which necessitated the need to develop sophisticated models like the ones developed by Kenneth Pitzer [27-31].

The concentration dependence of activity coefficients is most likely dependent on the local complexation structure of $\mathrm{LaCl}_{3}$ in the molten eutectic electrolyte. Quite a few studies using various experimental techniques like Raman Spectroscopy[32, 33], neutron diffraction[34-37] and x-ray diffraction[38-40] has demonstrated that for $\mathrm{LaCl}_{3}$, there exists a multitude of complexes that can be formed by $\mathrm{LaCl}_{3}$ with lanthanum ions capable of having variable coordination numbers. In 2010, Okamoto et al.[41] conducted XAFS tests and MDS studies of a LiCl-KCl- $\mathrm{LaCl}_{3}$ molten salt mixture. They studied mixtures containing from 1 to 100 mole $\% \mathrm{LaCl}_{3}$. They demonstrated that the coordination number and inter-ionic distance increase 
with increasing concentration of $\mathrm{LaCl}_{3}$. This and other data available in that paper clearly demonstrate that the coordination chemistry of the dissolved La species is dependent on the concentration of the total La present in the mixture. This concentration dependence of complexation reactions of $\mathrm{LaCl}_{3}$ and ability of $\mathrm{LaCl}_{3}$ to have a multitude of coordination numbers likely explains the observed trends for apparent potentials and activity coefficients reported here.

A graph of OCP vs. $\operatorname{Ln}\left(X_{\mathrm{LaCl}_{3}}\right)$ for the three main tests reported here is shown in Figure 10. As expected, a linear relationship is observed between the two plotted quantities. The slope of the line is equal to RT/nF. Equating the slope to is expected value of $\mathrm{RT} / \mathrm{nF}$ and calculating $\mathrm{n}$, we obtain the following values; $\mathrm{n}=2.70,2.80$ and 2.21 for tests with $0,0.69$ and 1.40 mole $\% \mathrm{CsCl}$ respectively. Now for the first two cases, the value of $\mathrm{n}=2.70$ and $\mathrm{n}$ $=2.80$ is relatively close to the expected value of the expected value of $n=$ 3. In the presence of 1.40 mole $\% \mathrm{CsCl}$, the value of $\mathrm{n}=2.21$ is significantly lower than the value than the one expected. This perceived trend broadly reflects the trends observed in the measured properties. Properties of $\mathrm{LaCl}_{3}$, tests with 0 and 0.69 mole $\% \mathrm{CsCl}$ are fairly similar. However the case with 1.40 mole $\% \mathrm{CsCl}$ shows much lower value of $\mathrm{n}$, which implies that $\mathrm{n}=2$. This evidence indicates that the presence of higher concentrations of $\mathrm{CsCl}$ does indeed seem to affect the local coordination structure of $\mathrm{LaCl}_{3}$.

The effect of $\mathrm{CsCl}$ on the coordination chemistry of $\mathrm{LaCl}_{3}$ is much harder to determine theoretically based on previously published open literature. While there has been no study to date of the $\mathrm{LiCl}-\mathrm{KCl}-\mathrm{CsCl}-\mathrm{LaCl}_{3}$ systems. There is some evidence in the literature of alkali metals play a role in altering 
the local coordination structure in molten salts with an increased efficiency going from Li to Cs[42]. These perturbations in the local coordination chemistry of molten salt most likely translate into the effects of $\mathrm{CsCl}$ reported in this paper.

In molten salt systems, for $\mathrm{LaCl}_{3}$, an initial increase in the activity coefficient in the species can be attributed to the increase in the concentration of the lanthanum. It is likely that at these low concentrations, the concentration of lanthanum is not high enough to engender the formation of higher order complexes as the coordination number of lanthanum is very low. The reduction in the activity coefficient can certainly be attributed to the formation of higher order complexes as reported in literature. We know from thermodynamic literature for both aqueous and molten salt chemistry, the existence of "interaction parameters" that heavily influence the activity coefficients. The presence of other lanthanum ions and Cs ions most certainly influence the coordination chemistry of $\mathrm{LaCl}_{3}$, manifesting itself as a systematic variation in the activity coefficients and apparent potentials.

\section{Conclusions}

This paper sheds new light on our experimental understanding of the behavior of lanthanum chloride in molten eutectic $\mathrm{LiCl}-\mathrm{KCl}$ salt. Experimental studies are reported in this paper on the behavior of the activity coefficient and apparent potential of the $\mathrm{LaCl}_{3}$ in molten $\mathrm{LiCl}-\mathrm{KCl}$ eutectic salt. Experimental evidence indicates that both the activity coefficient of $\mathrm{LaCl}_{3}$ and the apparent potential exhibit a dependence on the concentration of $\mathrm{LaCl}_{3}$ present in the solution. Both of the properties are observed to first increase 
and subsequently decrease with the concentration of $\mathrm{LaCl}_{3}$.

In addition, we observed that the presence of an alkali metal like $\mathrm{CsCl}$ does seem to affect the aforementioned two properties. While a low concentration of $\mathrm{CsCl}$ does not seem to affect the $\mathrm{LaCl}_{3}$ present, a higher concentration of Cs present does indeed seem to affect both the apparent potential and activity coefficient of $\mathrm{LaCl}_{3}$. This influence of higher concentrations of $\mathrm{CsCl}$ on the electrochemical and thermodynamic properties of $\mathrm{LaCl}_{3}$ is determined to be statistically significant. Further work may be needed to examine the effects of high concentrations of $\mathrm{CsCl}$ on the activity of $\mathrm{LaCl}_{3}$.

\section{Acknowledgment}

This work was supported by the United States Department of Energy's Nuclear Energy University Program [grant number 14-6489]. We gratefully acknowledge both the support of the Department of Energy and the Ohio State University, which is the lead institution on the project. In particular, we appreciate the support from and valuable technical discussions with Dr. Jinsuo Zhang from the Ohio State University. 
[1] J.-H. Yoo, C.-S. Seo, E.-H. Kim, H.-S. Lee, Nuclear Engineering and Technology 40 (2008) 581-592.

[2] H. Ohta, T. Inoue, Y. Sakamura, K. Kinoshita, Nuclear Technology 150 (2005) 153-161.

[3] H.-J. Choi, M. Lee, J. Y. Lee, Nuclear Engineering and Design 241 (2011) 3348-3356.

[4] P. Masset, R. J. Konings, R. Malmbeck, J. Serp, J.-P. Glatz, Journal of Nuclear Materials 344 (2005) 173-179.

[5] F. Lantelme, Y. Berghoute, Journal of the Electrochemical Society 146 (1999) 4137-4144.

[6] H. Tang, B. Pesic, Electrochimica Acta 119 (2014) 120-130.

[7] Y. Castrillejo, M. Bermejo, E. Barrado, A. Martınez, P. D. Arocas, Journal of Electroanalytical Chemistry 545 (2003) 141-157.

[8] M. Salanne, C. Simon, P. Turq, P. A. Madden, The Journal of Physical Chemistry B 112 (2008) 1177-1183.

[9] J. Zhang, Journal of Nuclear Materials 447 (2014) 271-284.

[10] W. Stumm, J. J. Morgan, Aquatic chemistry: Chemical Equilibria and Rates in Natural Waters, John Wiley \& Sons, 2012.

[11] M. Williamson, J. Willit, Nuclear Engineering and Technology 43 (2011) $329-334$. 
[12] J. A. Plambeck, Journal of Chemical \& Engineering Data 12 (1967) $77-82$.

[13] D. M. Gruen, R. A. Osteryoung, Annals of the New York Academy of Sciences 79 (1960) 897-907.

[14] H. A. Laitinen, C. H. Liu, Journal of the American Chemical Society 80 (1958) 1015-1020.

[15] A. J. Bard, L. R. Faulkner, Electrochemical methods: fundamentals and applications, volume 2, Wiley New York, ????

[16] M. Blander, Thermodynamic properties of molten salt solutions, Technical Report, Argonne National Lab., IL (USA), 1986.

[17] J. M. Prausnitz, R. N. Lichtenthaler, E. G. de Azevedo, Molecular thermodynamics of Fluid-Phase Equilibria, Prentice Hall PTR, 1998.

[18] I. Barin, Thermochemical Data of Pure Substances, Third Edition, Wiley-VCH Verlag GmbH, 1995.

[19] A. D. Pelton, Personal Communication, 2015.

[20] S. P. Fusselman, J. J. Roy, D. L. Grimmett, L. F. Grantham, C. L. Krueger, C. R. Nabelek, T. S. Storvick, T. Inoue, T. Hijikata, K. Kinoshita, Y. Sakamura, K. Uozumi, T. Kawai, N. Takahashi, Journal of The Electrochemical Society 146 (1999) 2573-2580.

[21] L. Yang, R. G. Hudson, Journal of The Electrochemical Society 106 (1959) 986-990. 
[22] O. Shirai, A. Uehara, T. Fujii, H. Yamana, Journal of Nuclear Materials 344 (2005) 142 - 145. Proceedings of the 11th International Symposium on Thermodynamics of Nuclear Materials.

[23] S. Kuznetsov, H. Hayashi, K. Minato, M. Gaune-Escard, Journal of Nuclear Materials 344 (2005) 169 - 172. Proceedings of the 11th International Symposium on Thermodynamics of Nuclear Materials.

[24] V. S. Bagotsky, Fundamentals of electrochemistry, volume 44, John Wiley \& Sons, 2005.

[25] A. Milchev, Electrocrystallization: fundamentals of nucleation and growth, Springer Science \& Business Media, 2002.

[26] Y. Wang, W. Zhou, J. Zhang, Journal of Nuclear Materials 478 (2016) $61-73$.

[27] K. S. Pitzer, The Journal of Physical Chemistry 77 (1973) 268-277.

[28] K. S. Pitzer, G. Mayorga, The Journal of Physical Chemistry 77 (1973) 2300-2308.

[29] K. S. Pitzer, G. Mayorga, Journal of Solution Chemistry 3 (1974) 539546.

[30] K. S. Pitzer, J. J. Kim, Journal of the American Chemical Society 96 (1974) 5701-5707.

[31] K. S. Pitzer, Journal of Solution Chemistry 4 (1975) 249-265. 
[32] G. Papatheodorou, Inorganic and Nuclear Chemistry Letters 11 (1975) 483-490.

[33] Y. Iwadate, H. Matsuura, A. Kajinami, K. Takase, N. Ohtori, N. Umesaki, R. Fujita, K. Mizuguchi, H. Kofuji, M. Myochin, Electrochemistry 77 (2009) 736-740.

[34] J. C. Wasse, P. S. Salmon, Journal of Physics: Condensed Matter 11 (1999) 1381.

[35] J. C. Wasse, P. S. Salmon, R. G. Delaplane, Physica B: Condensed Matter 276278 (2000) $433-434$.

[36] J. C. Wasse, P. S. Salmon, Journal of Physics: Condensed Matter 11 (1999) 9293.

[37] M.-L. Saboungi, D. L. Price, C. Scamehorn, M. P. Tosi, EPL (Europhysics Letters) 15 (1991) 283.

[38] Y. Okamoto, H. Hayashi, T. Ogawa, Japanese Journal of Applied Physics 38 (1999) 156.

[39] Y. Okamoto, H. Shiwaku, T. Yaita, H. Narita, H. Tanida, Journal of Molecular Structure 641 (2002) $71-76$.

[40] Y. Okamoto, P. Madden, Journal of Physics and Chemistry of Solids 66 (2005) 448 - 451. Proceedings of the 11th International Conference on High Temperature Materials Chemistry (HTMC-XI). 
${ }_{593}$ [41] Y. Okamoto, S. Suzuki, H. Shiwaku, A. Ikeda-Ohno, T. Yaita, P. A. $594 \quad$ Madden, The Journal of Physical Chemistry A 114 (2010) 4664-4671.

595 PMID: 20225902.

596 [42] A.-L. Rollet, M. Salanne, Annu. Rep. Prog. Chem., Sect. C: Phys. Chem. 597 107 (2011) 88-123. 


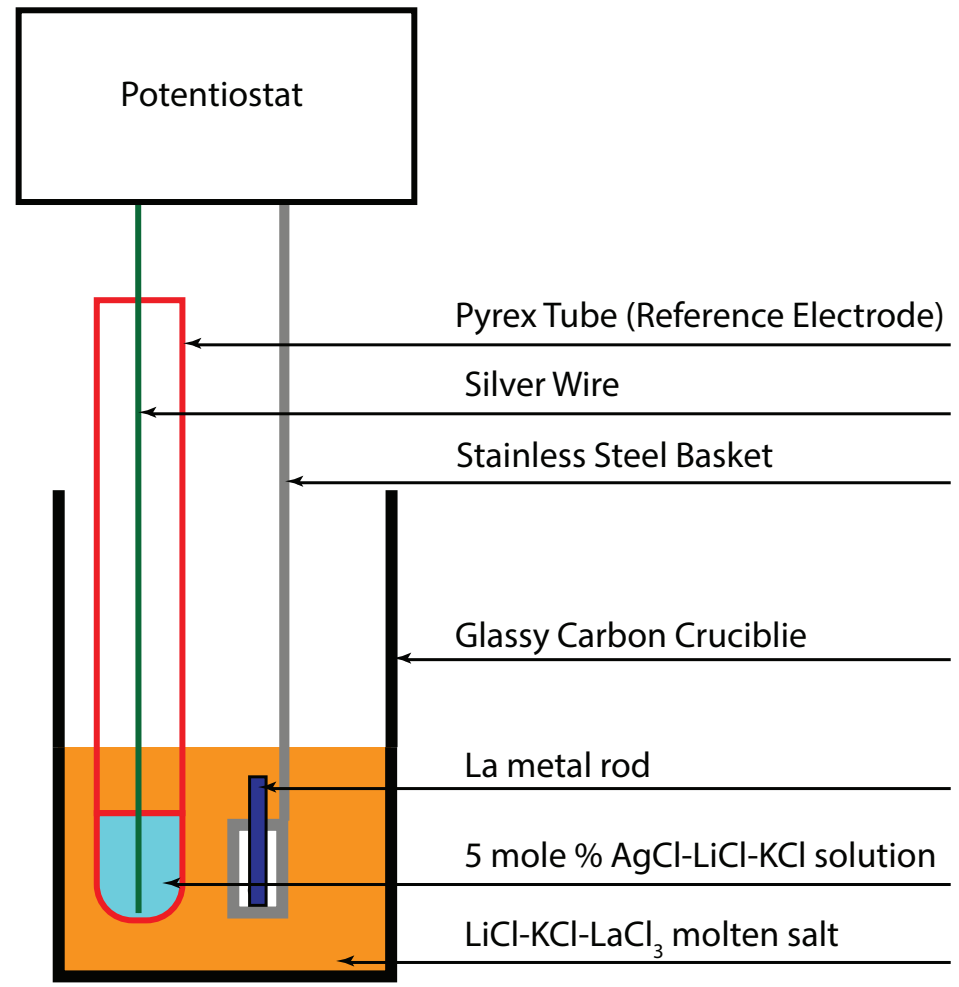

Figure 1: Schematic of the experimental set-up used for this work 


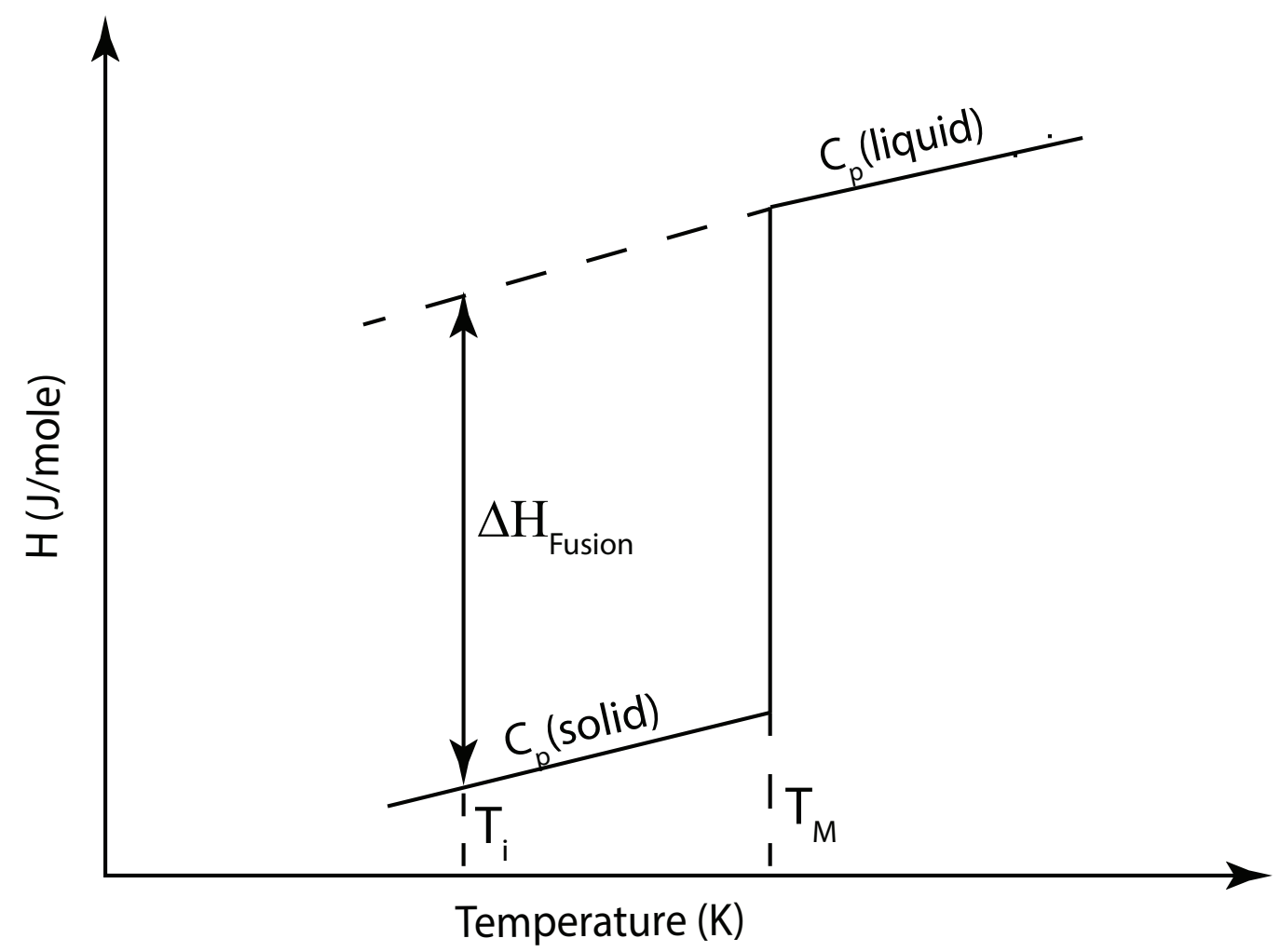

Figure 2: Schematic representation of a $\mathrm{H}$ vs. T Diagram 


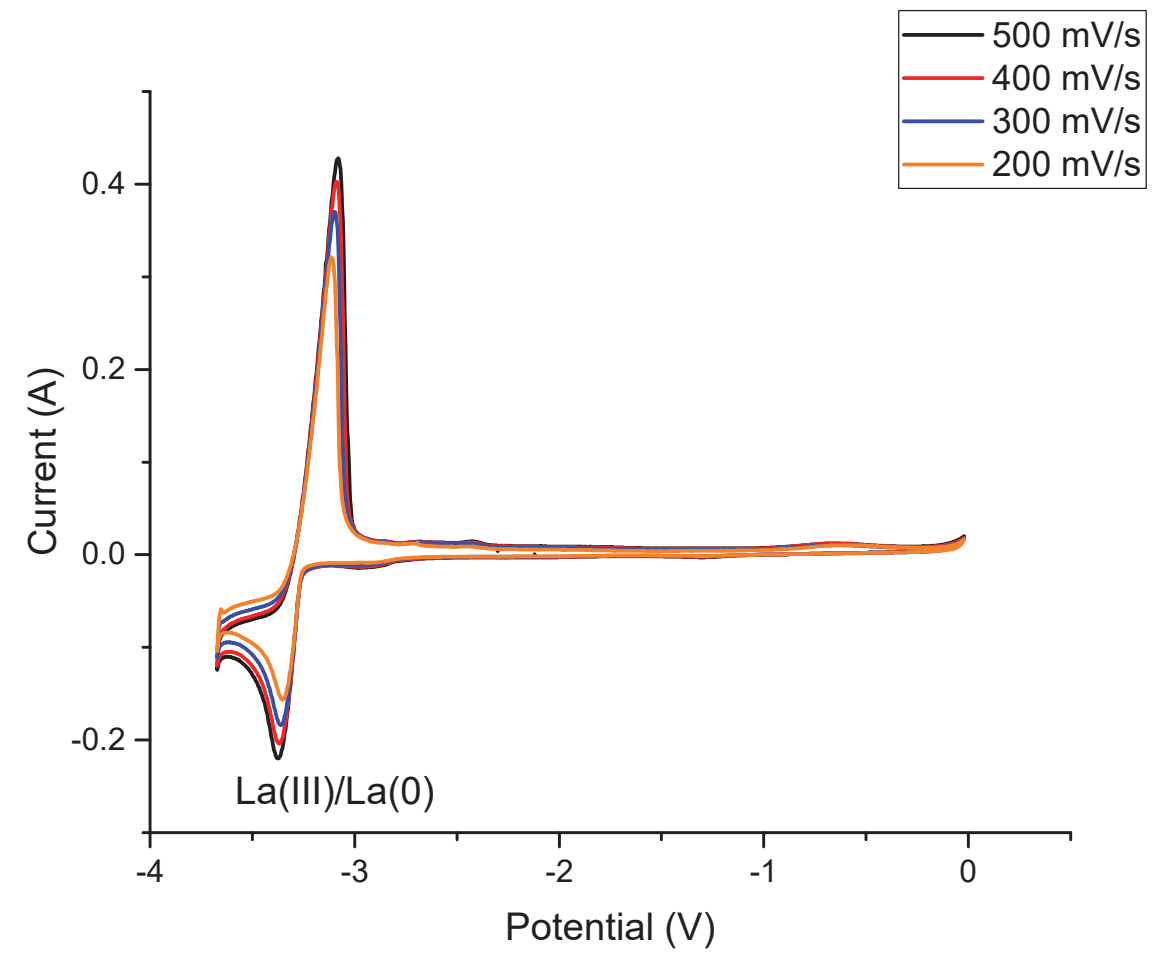

Figure 3: Cyclic voltammogram at four scan rates of 200, 300, 400 and $500 \mathrm{mV} / \mathrm{s}$ for $\mathrm{LaCl}_{3}$ (0.46 mole \%) in molten LiCl- $\mathrm{KCl}$ eutectic salt performed at $773 \mathrm{~K}$. Working Electrode: Glassy carbon rod ( $\phi=2 \mathrm{~mm})$, Counter Electrode: La metal rod, Reference Electrode: 5 mole $\% \mathrm{Ag} / \mathrm{AgCl}$. Potentials reported vs. $\mathrm{Cl}^{-} / \mathrm{Cl}_{2}$ couple. 


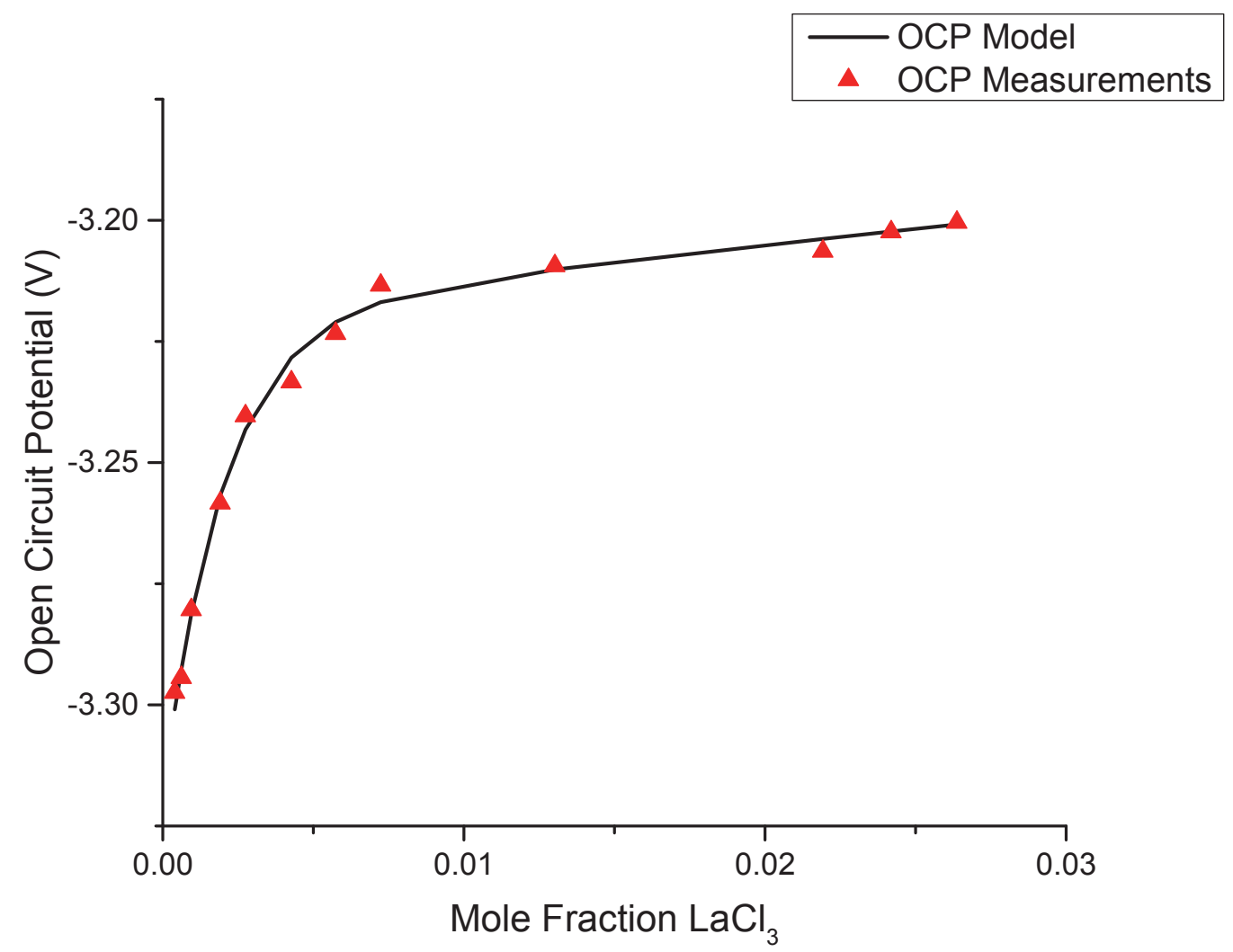

Figure 4: Experimental and modeled values of open circuit potential (vs. $\mathrm{Cl}^{-} / \mathrm{Cl}_{2}$ ) for $\mathrm{La} / \mathrm{La}(\mathrm{III})$ couple, plotted as a function of $\mathrm{LaCl}_{3}$ concentration at $773 \mathrm{~K}$. 


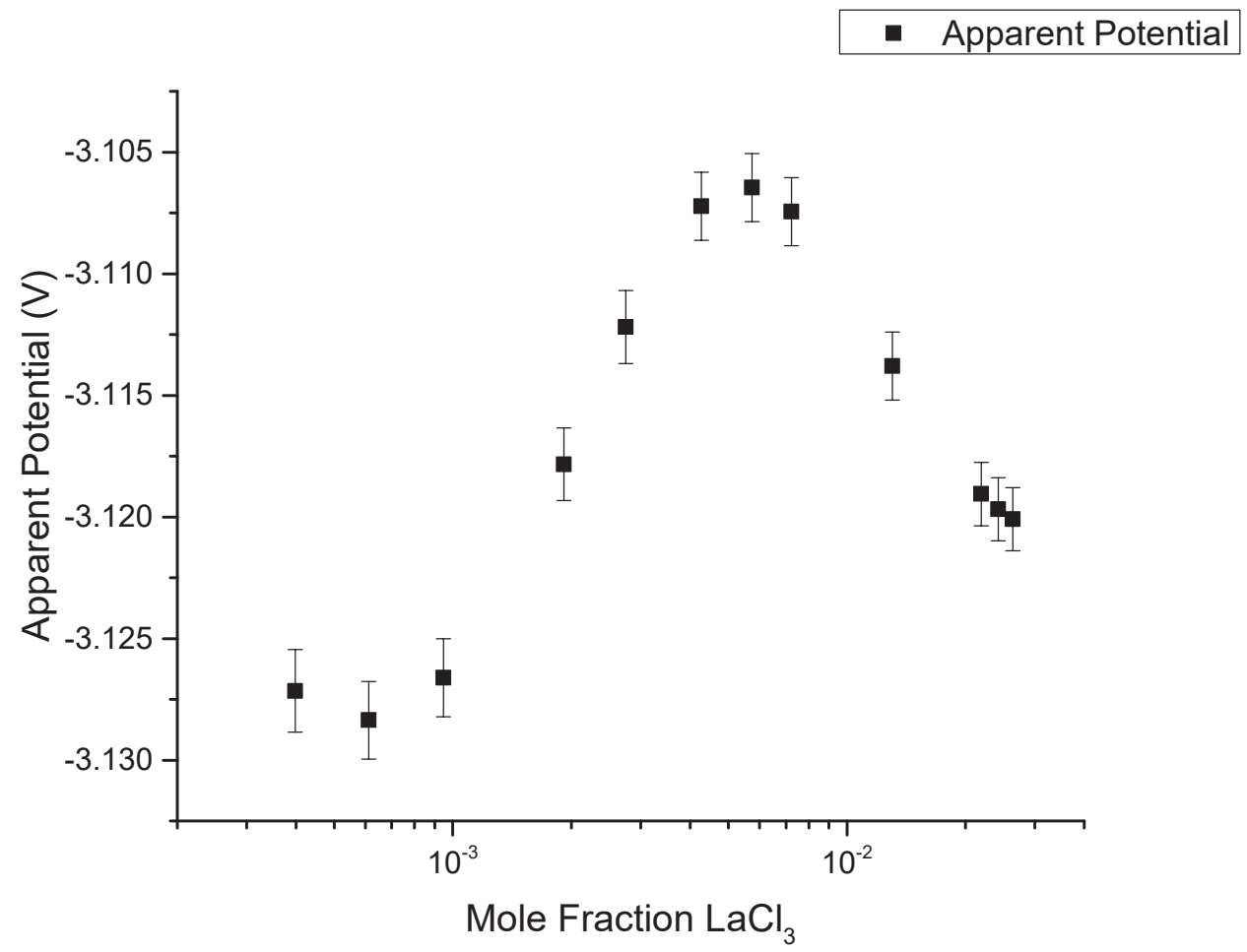

Figure 5: Apparent potential (vs. $\mathrm{Cl}^{-} / \mathrm{Cl}_{2}$ ) for $\mathrm{La} / \mathrm{La}(\mathrm{III})$ couple plotted as a function of $\mathrm{LaCl}_{3}$ concentration at $773 \mathrm{~K}$. 


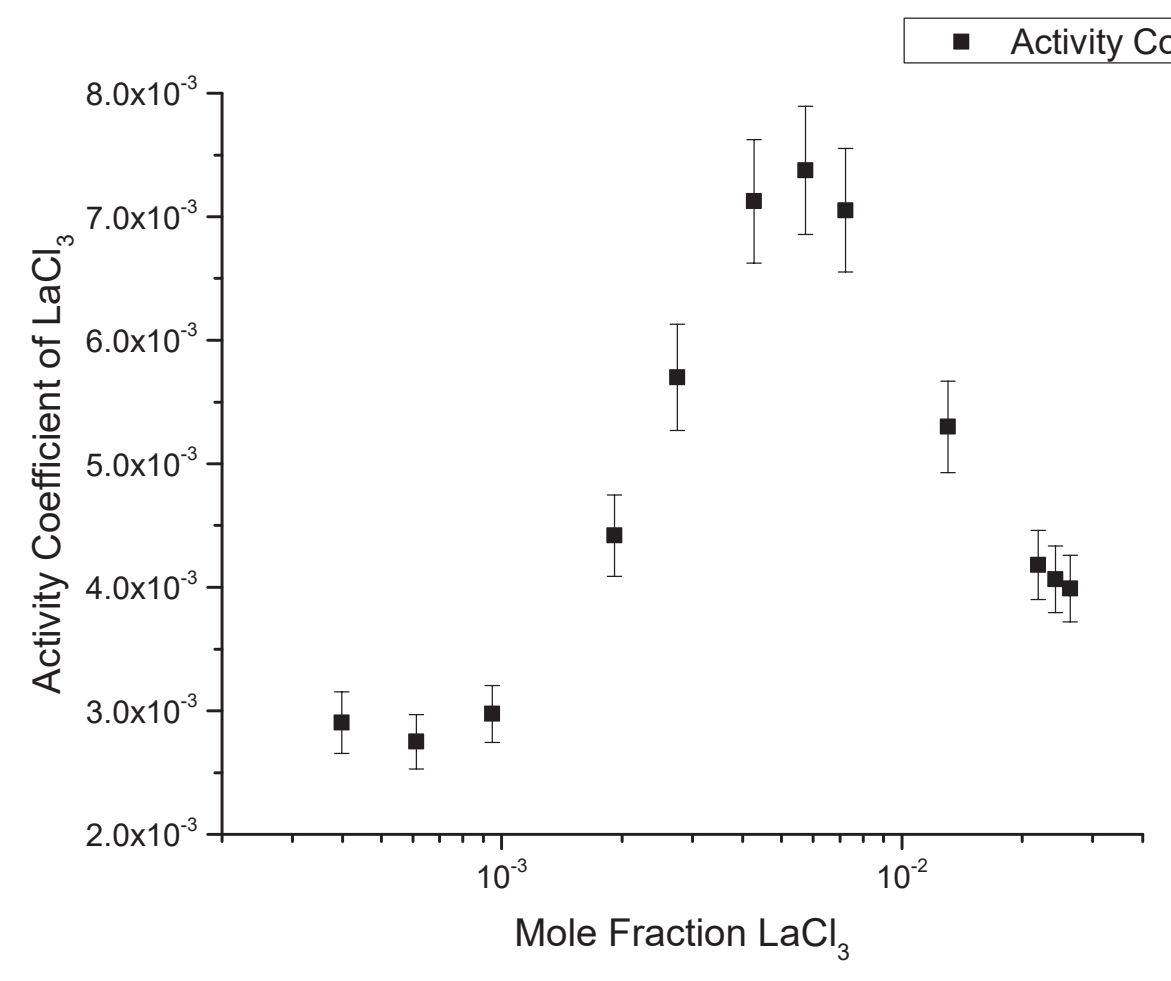

Figure 6: Activity Coefficient $\left(\gamma_{\mathrm{LaCl}_{3}}\right)$ of $\mathrm{LaCl}_{3}$ plotted as a function of $\mathrm{LaCl}_{3}$ concentration at $773 \mathrm{~K}$. 


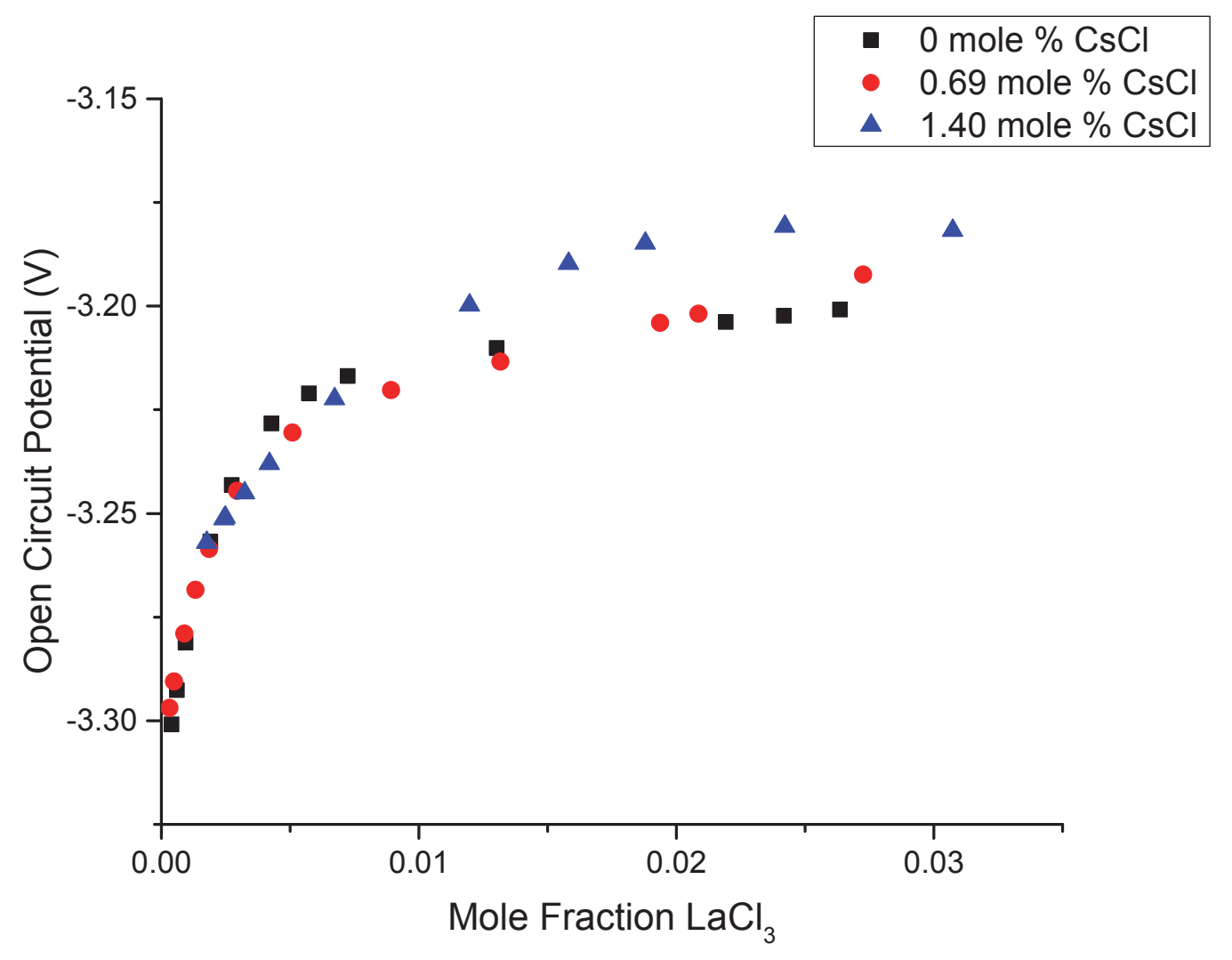

Figure 7: Open Circuit Potential (vs. $\mathrm{Cl}^{-} / \mathrm{Cl}_{2}$ ) for $\mathrm{La} / \mathrm{La}(\mathrm{III})$ couple plotted as a function of $\mathrm{LaCl}_{3}$ concentration for three independent concentrations of $\mathrm{CsCl} ; 0,0.69$ and 1.40 mole $\% \mathrm{CsCl}$ at $773 \mathrm{~K}$. 


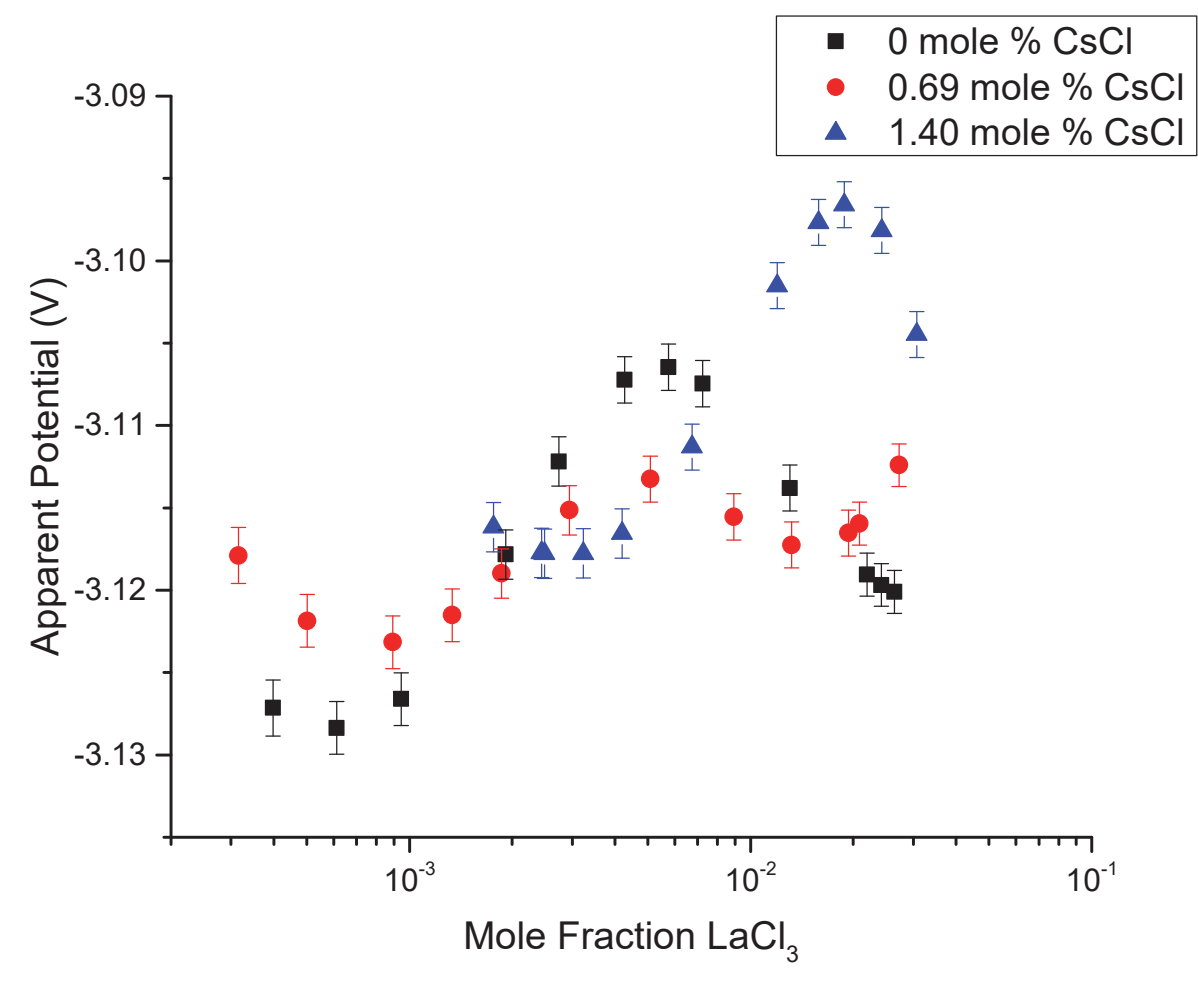

Figure 8: Apparent Potentials (vs. $\mathrm{Cl}^{-} / \mathrm{Cl}_{2}$ ) for La/La(III) couple plotted as a function of $\mathrm{LaCl}_{3}$ concentration for three independent concentrations of $\mathrm{CsCl} ; 0,0.69$ and 1.40 mole $\% \mathrm{CsCl}$ at $773 \mathrm{~K}$. 


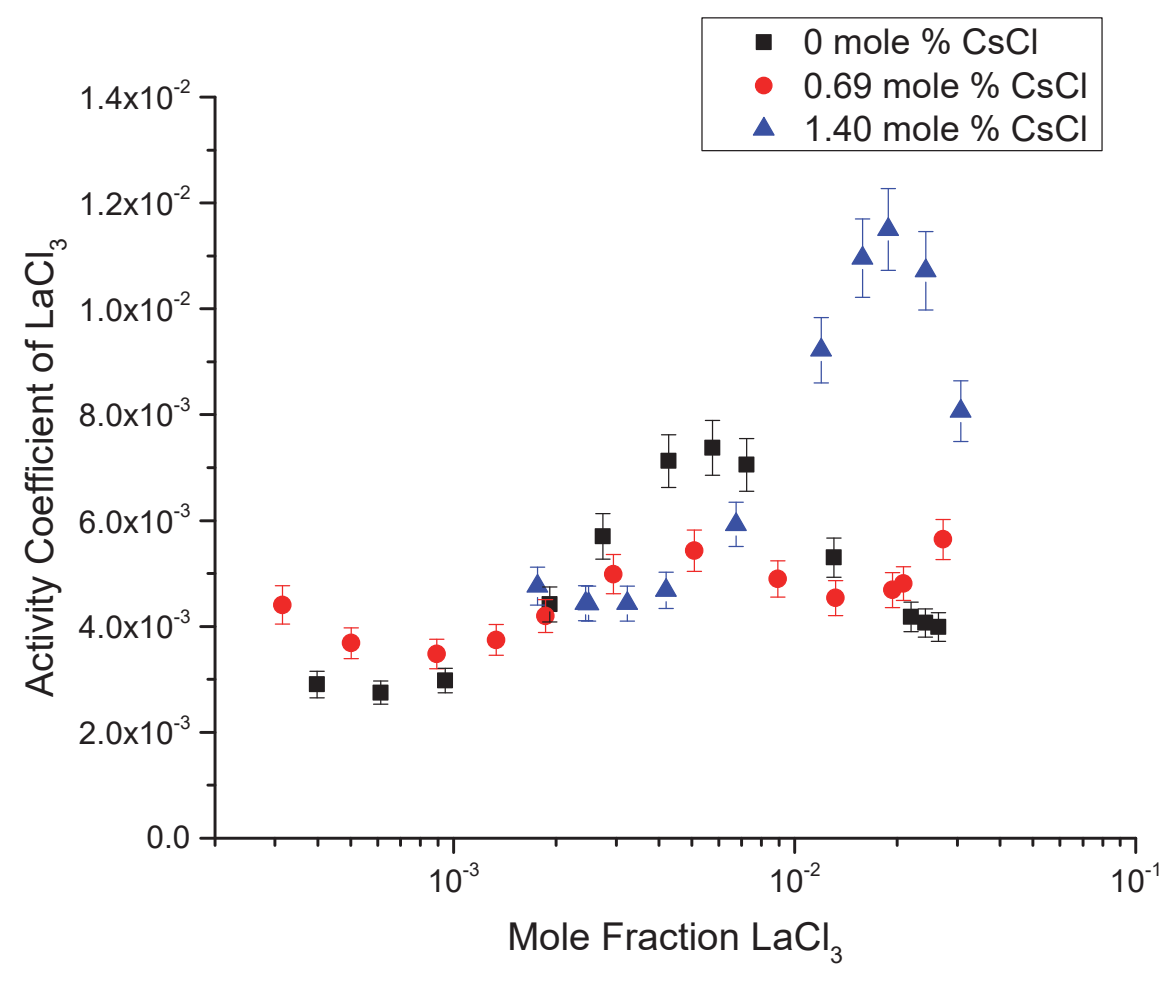

Figure 9: Activity Coefficient of $\mathrm{LaCl}_{3}\left(\gamma_{\mathrm{LaCl}_{3}}\right)$ plotted as a function of $\mathrm{LaCl}_{3}$ concentration for three independent concentrations of $\mathrm{CsCl} ; 0,0.69$ and 1.40 mole \% $\mathrm{CsCl}$ at 773 $\mathrm{K}$. 


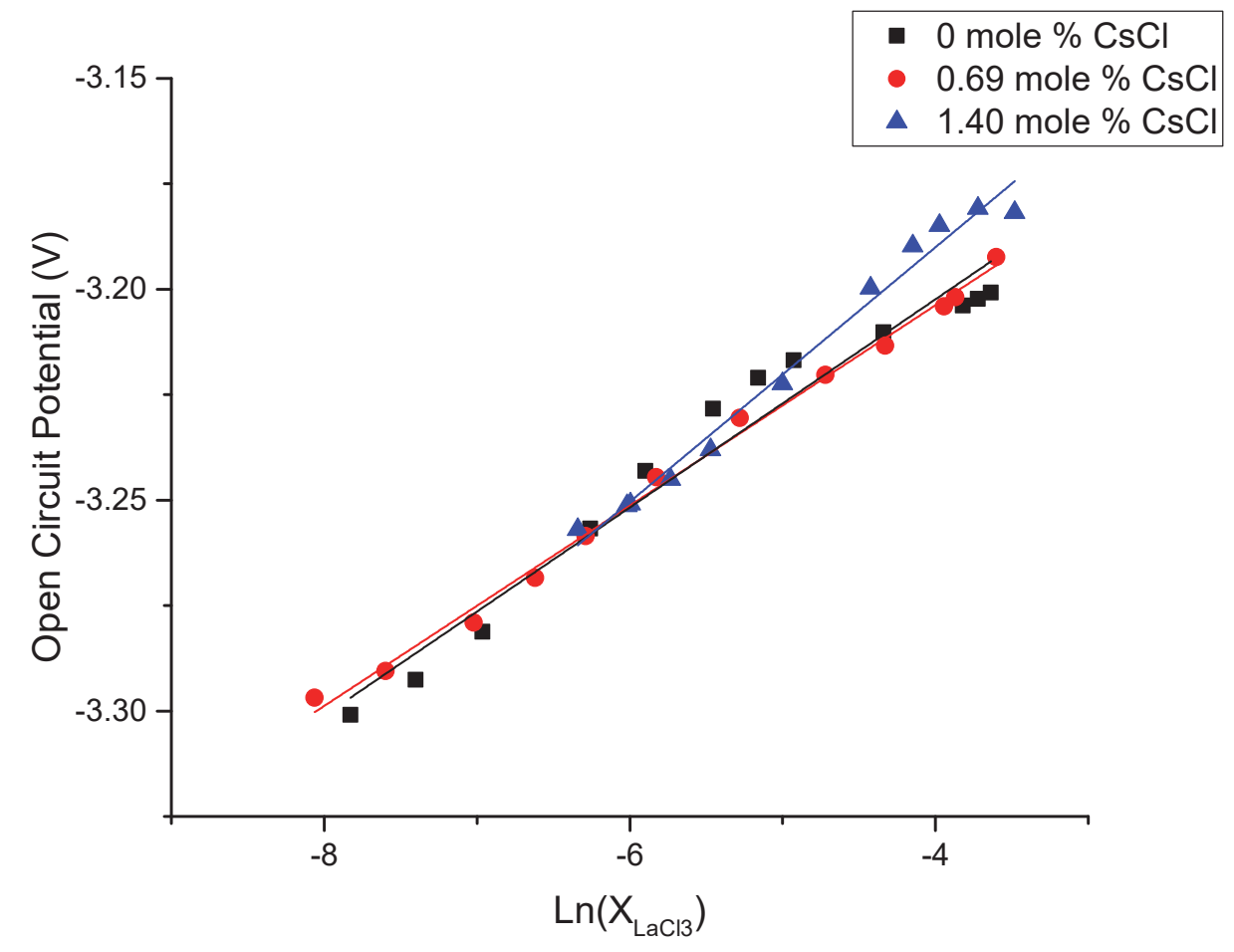

Figure 10: Figure of Open Circuit Potential (vs. $\mathrm{Cl}^{-} / \mathrm{Cl}_{2}$ ) plotted as a function of $\operatorname{Ln}\left(X_{\mathrm{LaCl}_{3}}\right)$. Figure shows plots for three independent concentrations of $\mathrm{CsCl} ; 0,0.69$ and 1.40 mole $\% \mathrm{CsCl}$ at $773 \mathrm{~K}$ respectively. 